\title{
Improved coagulation screening by an activated recalcification test
}

\author{
D. T. HUNTER AND J. L. ALLENSWORTH \\ From the Department of Pathology, the University of Utah College of Medicine, \\ Salt Lake City, Utah, U.S.A.
}

SYNOPSIS The conventional plasma recalcification test is improved by incubation of test plasma with Celite suspended in distilled water. This effectively activates factor XII and releases platelet factor 3, thereby markedly shortening the clotting time. The modified plasma recalcification test has several advantages that contribute to its usefulness as a general screening test for coagulation abnormalities. It is more precise and reproducible than any comparable test that assays a similar spectrum of coagulation factors.

The plasma recalcification test is an ideal screening procedure by which to evaluate the total coagulation mechanism. It assesses all plasma coagulation factors except for factor IV (ionized calcium) and it is sensitive to quantitative and qualitative changes in platelets (Caldwell, 1957). In addition, it is simple and economical to perform. The one characteristic of the conventional recalcification test that limits its usefulness is its wide range of normal values (90-240 seconds). The disadvantages of an extended range of this magnitude are insensitivity to slight deficiencies of second stage factors and excessive consumption of technical time. We succeeded in shortening and narrowing the normal limits of this test. The modified procedure is described in this paper and its application as a coagulation screening test is presented.

\section{METHOD}

PRINCIPLE Test plasma is incubated with Celite $^{1}$ suspended in distilled water. The Celite activates factor XII while the distilled water implements release of platelet factor 3 into the plasma. The addition of optimal ionic calcium allows the coagulation mechanism to progress to completion.

PROCEDURE 1 Venous blood is collected and immediately mixed with $0 \cdot 1 \mathrm{M}$ sodium oxalate in the exact ratio of 9 parts of blood to 1 part of anticoagulant. (Citrate or E.D.T.A. may be used at similar molar concentration.)

2 Centrifuge slowly at 1,500 r.p.m. for approximately 10 minutes.

'John Manville, N.Y.C., N.Y.

Received for publication 28 October 1966.
3 Incubate $0.1 \mathrm{ml}$. of harvested platelet-rich test plasma with $0.1 \mathrm{ml}$. of $1 \% \mathrm{w} / \mathrm{v}$ Celite suspension in distilled water for at least six minutes at $37^{\circ} \mathrm{C}$.

4 Add and mix $0.1 \mathrm{ml}$. of warm $\left(37^{\circ} \mathrm{C}\right.$.) $0.025 \mathrm{M}$ calcium chloride.

5 Tilt and record time of clot formation following addition of calcium chloride.

NOTES ON TECHNIQUE 1 The procedure may be performed manually or on a semi-automated clot timer.

2 All tests should be performed in duplicate at $37^{\circ} \mathrm{C}$.

3 Test plasma may stay in contact with the red cell layer before testing.

4 Yield of platelets may be increased if the test specimen is aspirated from directly above the buffy layer.

5 Calcium chloride and Celite reagents are stable indefinitely if refrigerated.

6 Pooled normal fresh frozen plasma may be used as a control.

PATIENT DATA The procedure was employed as a screening test on 250 patients and 65 normal subjects. Activated cephalin clotting tests (Proctor and Rapaport, 1961) were performed in duplicate on all specimens. Other coagulation tests were performed as indicated. A summary of the patients screened is shown in Table $\mathrm{I}$.

\section{RESULTS}

The normal range for this modified recalcification procedure was established between 32 and 48 seconds, with a standard deviation in this range of 3.5 seconds. Comparative statistical studies between the modified recalcification and cephalin clotting tests at different ranges are shown in Table II.

Plasma that had been frozen clotted up to three 
TABLE 1

SUMMARY OF PATIENTS SCREENED BY THE MODIFIED RECALCIFICATION AND CEPHALIN CLOTTING TESTS

\begin{tabular}{|c|c|c|c|c|c|}
\hline Number & Category & $\begin{array}{l}\text { Modified } \\
\text { Recalcification } \\
\text { Test (sec.) }\end{array}$ & $\begin{array}{l}\text { Cephalin } \\
\text { Clotting } \\
\text { Test (sec.) }\end{array}$ & Other Studies & $\begin{array}{l}\text { Clinical } \\
\text { Bleeding }\end{array}$ \\
\hline $\begin{array}{l}65 \\
81\end{array}$ & $\begin{array}{l}\text { Normal } \\
\text { Coumarin } \mathbf{R}_{\mathbf{x}}\end{array}$ & $\begin{array}{l}32-48 \\
39 \cdot 4-99 \cdot 2 \\
19 \text { normal }\end{array}$ & $\begin{array}{l}28-45 \\
34 \cdot 8-92 \cdot 4 \\
48 \text { normal }\end{array}$ & $\begin{array}{l}3 \text { MRC over } 48 \mathrm{sec} \text {; repeated less than } 48 \mathrm{sec} \text {. } \\
\text { Prothrombin time } 16-56 \mathrm{sec} \text {. } \\
\text { 1 }\end{array}$ & $\begin{array}{l}\text { No } \\
3\end{array}$ \\
\hline 1 & Multiple myeloma & $51 \cdot 8$ & $22 \cdot 7$ & & Yes \\
\hline 1 & Hodgkin's disease & $65 \cdot 7$ & $46 \cdot 7$ & Platelets 15,000 & Yes \\
\hline 1 & Systemic lupus erythematosus & $62 \cdot 4$ & $53 \cdot 2$ & Circulating anticoagulant & Yes \\
\hline 1 & Idiopathic thrombocytopenia & $66 \cdot 2$ & $49 \cdot 2$ & Platelets 90,000 & Yes \\
\hline 1 & Classical haemophilia & $113 \cdot 2$ & $60 \cdot 2$ & A.H.G. $1 \%$ w/anti-A.H.G. & Yes \\
\hline 1 & Idiopathic, neonatal & $72 \cdot 7$ & $47 \cdot 7$ & Platelets normal & Yes \\
\hline 1 & Cirrhosis & $94 \cdot 6$ & $83 \cdot 2$ & Prothrombin time $20.0 \mathrm{sec}$. & Yes \\
\hline 1 & Hepatitis & $79 \cdot 4$ & $111 \cdot 1$ & & \\
\hline 1 & Fibrinolysis & $60 \cdot 7$ & $50 \cdot 2$ & Complete lysis of clot at $24 \mathrm{hr}$. & Yes \\
\hline 1 & Hepatitis & 62.6 & $100 \cdot 6$ & Prothrombin time $19.7 \mathrm{sec}$. & Yes \\
\hline 1 & Acute myeloblastic leukaemia & $82 \cdot 7$ & $38 \cdot 4$ & Platelets 24,000 & Yes \\
\hline 1 & Idiopathic circulating anticoagulant & $140 \cdot 2$ & $109 \cdot 2$ & & \\
\hline 1 & Chronic lymphatic leukaemia & $63 \cdot \overline{2}$ & $31 \cdot 0$ & Platelets 80,000 & Yes \\
\hline 1 & Heparin $\mathbf{R}_{\mathbf{x}}$ & $72 \cdot 6$ & $56 \cdot 7$ & Lee-White $12 \mathrm{~min} .30 \mathrm{sec}$. & Yes \\
\hline 1 & Heparin $\mathbf{R}_{\mathbf{x}}$ & 63.9 & $45 \cdot 8$ & Lee-White 9 min. $30 \mathrm{sec}$. & Yes \\
\hline 1 & $\begin{array}{l}\text { Milk allergy with gastrointestinal } \\
\text { bleeding }\end{array}$ & $68 \cdot 5$ & $55 \cdot 2$ & Milk antibodies present $\pm 30 \mathrm{ml} . /$ day blood loss & Yes \\
\hline 1 & Classical haemophilia & $162 \cdot 3$ & $80 \cdot 3$ & A.H.G. $1 \%$ & Yes \\
\hline 1 & Aspirin intoxication & $56 \cdot 3$ & $52 \cdot 4$ & Prothrombin time 17.5 & No \\
\hline 1 & Thrombocytopathy, idiopathic & $64 \cdot 8$ & $30 \cdot 8$ & Platelets 250,$000 ; 90+\%$ abnormal & Yes \\
\hline 1 & Hageman deficiency & $115 \cdot 2$ & $\mathbf{7 4 \cdot 3}$ & Rectified by coated tube & No \\
\hline 1 & Thrombasthenia, congenital & $55 \cdot 3$ & $28 \cdot 7$ & No platelet adherence; abnormal T.G.T. & Yes \\
\hline 1 & Thrombasthenia, congenital & $71 \cdot 5$ & $37 \cdot 1$ & No platelet adherence & Yes \\
\hline 4 & Coumarin $\mathbf{R}_{\mathbf{x}}$ & $49 \cdot 1-57 \cdot 2$ & $37 \cdot 0-43 \cdot 3$ & $\begin{array}{l}\text { Prothrombin time }<16 \text { sec.; two with factor IX } \\
\text { deficiency }\end{array}$ & No \\
\hline 1 & Uraemia w/hypocalcemia & $42 \cdot 3$ & $40 \cdot 5$ & Ionized calcium $1.5 \mathrm{mg} . / 100 \mathrm{ml}$. & No \\
\hline 1 & Normal w/added $\mathrm{Ca}^{++}$ & $34 \cdot 7$ & $31 \cdot 8$ & Total serum calcium $21 \mathrm{mg} . / 100 \mathrm{ml}$. & No \\
\hline 3 & Thrombasthenias, $2 \%$ uraemia & $58 \cdot 4$ & $47 \cdot 3$ & Platelets $>200,000$ & No \\
\hline & & $\begin{array}{l}49 \cdot 5 \\
56 \cdot 5\end{array}$ & $\begin{array}{l}36 \cdot 1 \\
40 \cdot 6\end{array}$ & $\begin{array}{l}\text { Poor clot retraction } \\
\text { No platelet adherence }\end{array}$ & $\begin{array}{l}\text { No } \\
\text { No }\end{array}$ \\
\hline
\end{tabular}

TABLE II

TABULAR COMPARISON OF RECALCIFICATION AND CEPHALIN CLOTTING TESTS

Recalcification Test

Cephalin

Clotting

Test

1 Normal limits

2 Standard deviation $<49 \mathrm{sec}$.

3 Standard deviation 50-59 sec.

4 Standard deviation $>60 \mathrm{sec}$.

5 Cost

6 Platelet effect

7 Factors assayed

8 False positives ${ }^{1}$

9 False negatives ${ }^{2}$

10 Temperature effect

11 Pre-incubation time

12 Specific conditions detected:
a) Defibrination syndrome
b) Thrombocytopathy
c) Thrombasthenia
d) Thrombocytopenia
e) First stage deficiency
f) Second stage deficiency
g) Heparin sensitivity

h) Other anticoagulants
$32-48 \mathrm{sec}$.

$3.5 \mathrm{sec}$.

$5 \cdot 1 \mathrm{sec}$.

$6.9 \mathrm{sec}$.

Insignificant

Predictable

Platelet factor 3 ,II, V, VII, VIII-XII

$5 \%$

Minimum

Not critical

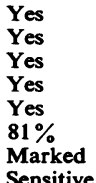

$28-45$ sec.

$3.3 \mathrm{sec}$.

$6.2 \mathrm{sec}$.

$12 \cdot 7 \mathrm{sec}$.

Significant

Variable

II, V, VIII-XII

$0 \%$

Significant

Critical

No

No

No

No

Yes

$69 \%$

Minimum

Insensitive

${ }^{1}$ As evaluated against normal prothrombin times. Two specimens were shown to have limiting factor IX.

${ }^{2}$ As evaluated against abnormal prothrombin times. All specimens 'missed' by the recalcification test were also missed by the cephalin clotting test. 
seconds sooner than fresh plasma. This is due to maximal platelet lysis following freezing. Reproducibility was good within four hours following collection, after which time unpredictable variables occurred. Table III compares the average clotting times of 10 random plasma specimens performed with and without distilled water and Celite. The study carried out using plain saline without Celite corresponds to the conventional plasma recalcification procedure (Caldwell, 1957).

\section{TABLE III}

COMPARISON OF EFFECTS OF CELITE SUSPENSION AND DISTILLED WATER ON RECALCIFICATION CLOTTING TIMES

\begin{tabular}{lllll} 
& $\begin{array}{l}\text { Celite-water } \\
(\mathrm{sec} .)\end{array}$ & $\begin{array}{l}\text { Celite-saline } \\
(\mathrm{sec} .)\end{array}$ & $\begin{array}{l}\text { Water } \\
(\mathrm{sec} .)\end{array}$ & $\begin{array}{l}\text { Saline } \\
(\mathrm{sec} .)\end{array}$ \\
\hline Mean & 56.9 & 67.8 & 92.9 & 122.6 \\
Range & $37.9-68 \cdot 7$ & $42.7-100 \cdot 4$ & $70.8-148.5$ & $96.9-194 \cdot 7$
\end{tabular}

Figure I shows a curve resulting from the serial dilution of Diagnostic Plasma ${ }^{\mathbf{R}}$ with normal saline,

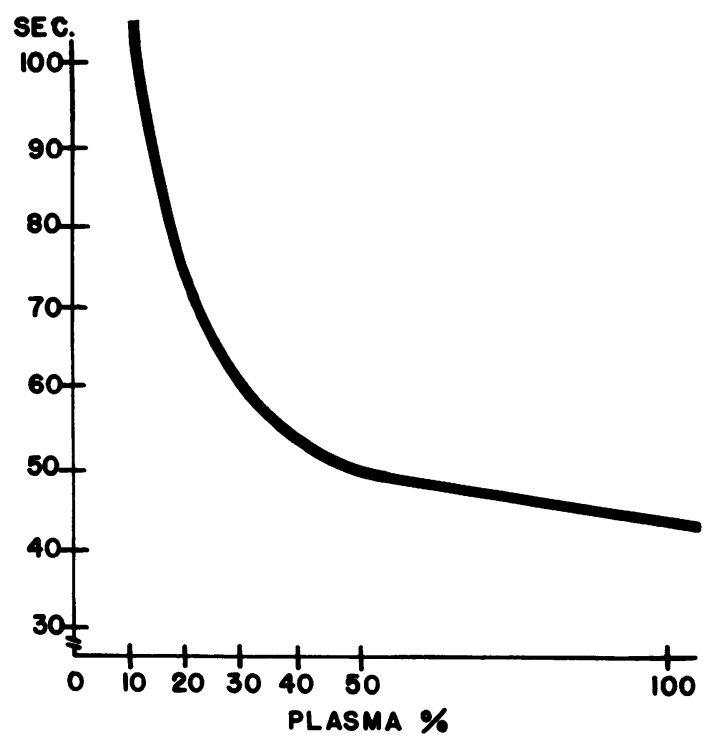

FIG. 1. This plasma-saline dilution curve follows the typical pattern seen in coagulation dilution studies. A straight line is assumed on log-log graph paper. While the minimal slope of the curve in the 50-100\% range will obscure some low-grade factor deficiencies, latent bleeding states will almost always manifest sufficient factor depletion to give abnormal results.

while Fig. 2 shows the quantitative effect of platelets. Optimal calcium concentration was determined by the titration shown in Figure 3.

In all of these dilution studies reproducibility was

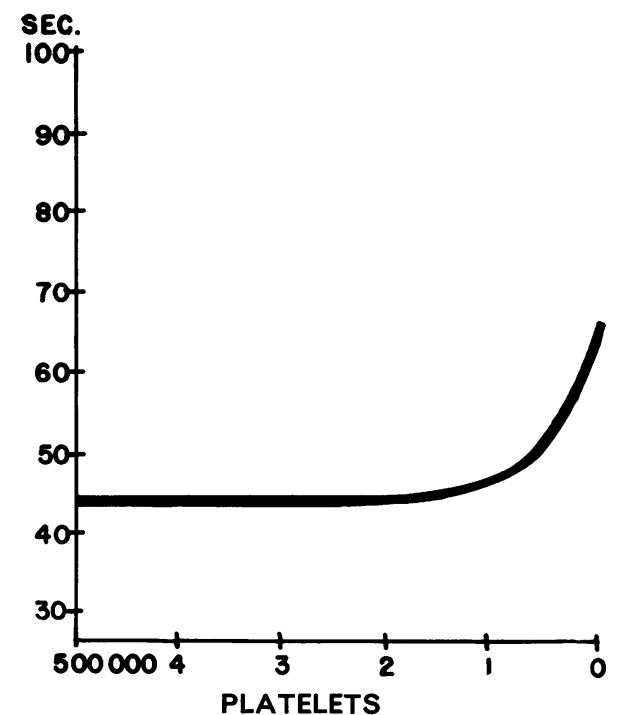

FIG. 2. The test system is extremely sensitive to platelet deficiencies. In addition, qualitative abnormalities of platelets will produce prolonged clotting times.

greatest when plasma factors were optimal. When one or more factors became sub-optimal, variation increased and bore an inverse relationship to the slope of the dilution curve. Comparative studies on the effects of environmental temperatures ranging between $15^{\circ}$ and $40^{\circ} \mathrm{C}$. on the clotting times of the modified recalcification test and the cephalin clotting

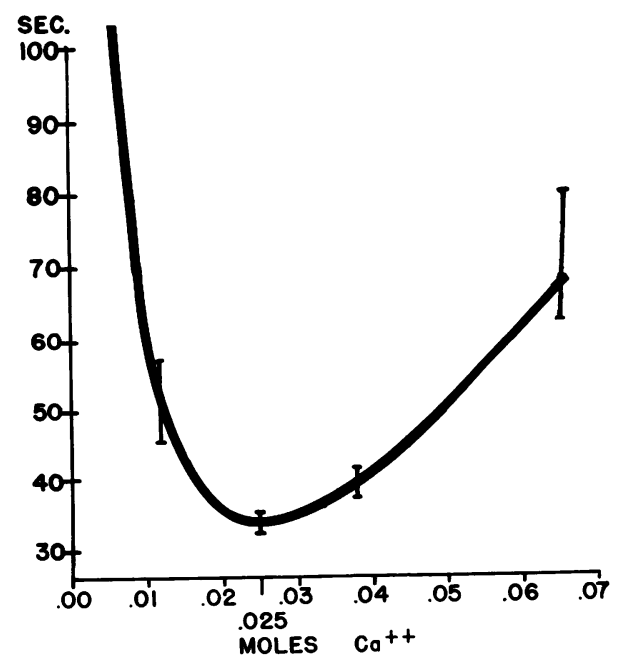

FIG. 3. The test system is very sensitive to calcium concentrations. Optimal ionized calcium will assure both minimal standard deviation and clotting time. 
test indicated that the recalcification test was little affected by temperature change, while the latter assay showed variations up to five seconds. It was observed that incubation time was critical in the activated cephalin clotting test; however, the length of pre-incubation had little effect on clotting time in the recalcification test between six and 60 minutes. Beyond 10 minutes the clotting time seen in the cephalin clotting procedure extended.

The effects of haemolysis, chylomicra, and macroglobulins on the test system were negligible. Studies performed using added epsilon aminocaproic acid to neutralize fibrinolysins in test plasma (Ablondi, Hagan, Philips, and De Renzo, 1959) showed no adverse effect on the test procedure. Increased fibrinolytic activity may be detected by either or both of two methods: ( $a$ ) visual observation of clot lysis (von Kaulla and Schultz, 1958); or (b) inversion of the tube containing the clot and observation for clot separation from the container (Thornes, 1963). As little as $30 \mathrm{mg} . / 100 \mathrm{ml}$. of fibrinogen will give visual clot formation.

If plasma is diluted 1 in 3 with distilled water before testing, a very sensitive assay of second stage factors can be made. Under routine clinical conditions this modification is unnecessary to detect potential bleeding situations.

The modified recalcification test was found to be sensitive to levels below $60 \%$ of first stage factors and $40 \%$ of second stage factors. Studies on plasma from heparinized animals showed a typical circulating anticoagulant effect by the titration technique (Conley, Hartmann and Morse, 1949) using the modified recalcification system.
The results of 315 screening tests are shown in Table I. These were performed over a 12-month period on selected patients. Significant platelet abnormalities were always detected by the recalcifcation test and were generally missed by the cephalin clotting test. Over $80 \%$ of patients on coumarin therapy gave elevated recalcification times while fewer than $50 \%$ of these were abnormal by the cephalin clotting test. With rare exceptions, the recalcification test showed a greater degree of abnormality than did the cephalin test.

\section{DISCUSSION}

By implementing factor XII activation (Ratnoff and Rosenblum, 1958) and platelet factor 3 release (Ulutin and Karaca, 1959; Lovric and Margolis, 1964), the plasma recalcification time is markedly shortened. This shortening of the clotting time gives greater sensitivity in evaluating all clotting factor deficiencies than the conventional recalcification method.

The sensitivity of the modified recalcification test system to quantitative and qualitative platelet abnormalities and its precision in assessing these abnormalities makes it possible to assay a broader spectrum of disease than the cephalin clotting test can detect. Although the cephalin clotting method is supposedly unaffected by platelet content, endogenous platelet factor 3 does, indeed, shorten the clotting time to the detriment of consistent results. It was also observed that phospholipid of animal origin gave shorter clotting times than vegetable phospholipid. These variables and inconsistencies of

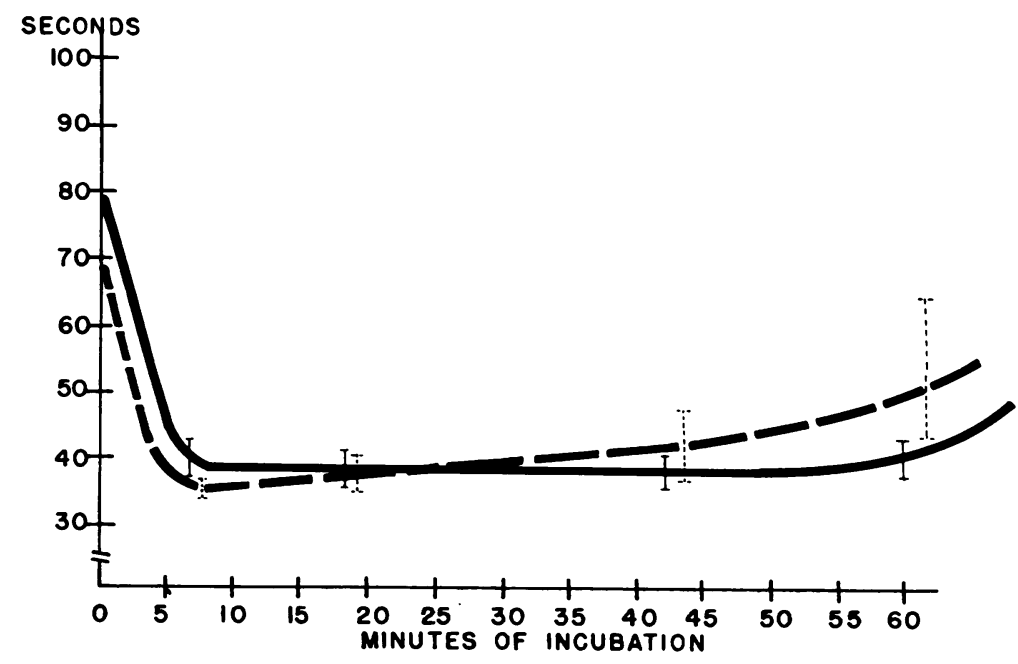

FIG. 4. Comparative studies on the modified recalcification test and the cephalin clotting test, showing the effects of extended incubation. 
the artificial system would indicate that a physiological system employing the patients' own platelets to supply platelet factor 3 is highly desirable. The cephalin clotting test also fails to detect factor VII deficiencies.

These considerations, plus the experimental results, would support the modified recalcification procedure as a general screening test of the coagulation system. When compared with the screening methods in current use (Caldwell, 1957; Hardisty and Macpherson, 1962; Nye, Graham, and Brinkhous, 1962; Lovric and Margolis, 1964; Hattersley, 1966), this broad-spectrum test appears to have considerable advantages.

In addition to its value in general screening, the modified plasma recalcification test may be used with facility and precision in all procedures employing the conventional recalcification test. It may be used to detect and titre circulating anticoagulants; it lends itself to substitution studies to identify deficient factors; and, it may be used to estimate crudely fibrinogen and fibrinolysin levels. Preliminary work indicates that the test is sufficiently sensitive to qualitative platelet disorders to permit semi-quantitation of thrombocytopathies and thrombasthenias (Ulutin and Karaca, 1959).

False positive results are occasionally encountered in normal people. Almost always subsequent studies have shown these to be due to artifactually diminished platelets, resulting from faulty collection of blood or from excessive centrifugation. A high percentage of 'false' positives $(5 \%)$ persisted in coumarin-anticoagulated patients who had normal prothrombin times. Two of these were studied in depth and shown to have limiting factor IX. False negative results are seen in low-grade, second-stage factor deficiencies. These second-stage deficiencies were also missed by the cephalin clotting test.

Although the Fibrometer ${ }^{\mathrm{R}}$ was used in this study to record the coagulation end point, manual methods will give comparable accuracy. The concentration of the Celite is not critical. Celite gives more precision than kaolin, due to the characteristic of Celite to stay in suspension.

Capillary and venous blood was collected from approximately 50 normal people and tested by the modified recalcification procedure. Capillary plasma clotted on the average three seconds sooner than venous plasma despite the fact that capillary blood was shown to be lower in both platelets and fibrinogen. This shortening was assumed to be due to tissue thromboplastin contamination. It is felt that capillary collection may be employed in special situations in which venous blood is unattainable, but that better accuracy is achieved by using venous blood.

\section{REFERENCES}

Ablondi, F. B., Hagan, J. J., Philips, M., and De Renzo, E. C. (1959). Arch. Biochem., 82, 153.

Caldwell, M. J. (1957). Amer. J. med. Technol., 23, 277.

Conley, C. L., Hartmann, R. C., and Morse, W. I., II. (1949). Bull. Johns Hopk. Hosp., 84, 255.

Hardisty, R. M., and Macpherson, J. C. (1962). Thrombos. Diathes. haemorrh. (Stuttg.), 7, 215.

Hattersley, P. G. (1966). J. Amer. med. Ass., 196, 436.

Lovric, V. A., and Margolis, J. (1964). Thrombos. Diathes. haemorrh. (Stuttg.), 11, 506.

Nye, S. W., Graham, J. B., and Brinkhous, K. M. (1962). Amer. J. med. Sci., 243, 279.

Proctor, R. R., and Rapaport, S. I. (1961). Amer. J. clin. Path., 36, 212. Ratnoff, O. D., and Rosenblum, J. M. (1958). Amer. J. Med., 25, 160. Thornes, R. D. (1963). J. Irish med. Ass., 53, 194.

Ulutin, O. N., and Karaca, M. (1959). Brit. J. Haemat., 5, 302.

von Kaulla, K. N., and Schultz, R. L. (1958). Amer. J. clin. Path., 29, 104. 